\title{
LAW, INCOMMENSURABILITY, AND CONCEPTUALLY SEQUENCED ARGUMENT
}

\author{
BRUCE GHAPMAN ${ }^{\dagger}$
}

\section{DIFFERENT PROCEDURES FOR PLURALISTIC CHOICE}

Suppose that a law school committee is charged with the task of awarding entrance scholarships to incoming first-year law students. Applicants for the scholarships are to be assessed on the basis of three criteria: financial need, scholarly ability, and community service. Of the students who have applied, suppose, too, that there is no student who is better than all the others on all of these criteria.

It is easy to imagine that many scholarship programs might announce selection criteria like these. Further, one can imagine that making the required choices in these situations is extremely difficult, both for each committee member as a matter of individual choice, and for the whole committee as a matter of social choice. Part of the problem, of course, typically will be that the relevant information is hard to come by, or that the competition is very keen, calling for the committee to make close judgments between students on each of the criteria considered on its own. But a far greater problem would seem to be that the imposed choice criteria are plural and incommensurable. Financial need, for example, does not appear to have much to do with scholarly ability. Indeed, to focus on the one seems to exclude consideration of the other, at least at the same moment-a bit like trying to see simultaneously both of the animal figures in the psy-

$\dagger$ Faculty of Law, University of Toronto. In addition to being presented at the University of Pennsylvania Law Review Symposium on Law and Incommensurability, this Article was presented to the Rationality and Society Workshop at the University of California at Berkeley and the Law and Economics Colloquium at New York University. I am grateful to the participants at all of these sessions and, more particularly, to Daniel Farber, Claire Finkelstein, Gillian Hadfield, Lewis Kornhauser, and Wayne Sumner for their helpful comments. Research funding from the Connaught Fund of the University of Toronto is also gratefully acknowledged. 
chologist's familiar rabbit-duck diagram. ${ }^{1}$ Further, it seems improper to construe these qualitatively different criteria as aspects of some larger overarching value that provides a common measure, or commensurability, for them all. Plural considerations are plural because they are different in their nature, and not because they simply differ in the amounts they offer of some common nature. ${ }^{2}$ For this reason, the assumption of commensurability does a kind of conceptual violence to the underlying values, converting genuine qualitative differences into merely quantitative ones. ${ }^{3}$

Of course, someone might say that meeting financial need and rewarding scholarship or community service are simply qualitatively different ways of maximizing (or at least increasing) overall social utility or welfare. But that too would seem to beg the very question at issue: How, exactly, can they be determinative of that same thing in such very different ways? The different criteria appear to be so genuinely external to one another that they frame the choice problem in a psychologically nonintegrable way, each engaging quite unrelated notions of overall social welfare.

The simplest committee example attests, therefore, to both the challenge and the pervasiveness of the problem of incommensurability of plural choice criteria. Surely the scholarship committee is not being asked to do anything extraordinary; its predicament of pluralistic choice would appear to be the rule rather than the exception in our lives. As individuals choosing our careers, for example, we constantly have to make choices that implicate, and are implicated by, very diverse values. For a law graduate there is an initial choice between pursuing a career as an academic or as a professional lawyer

' See Richard L. GREgoRy, EYE AND BRAIN 207 (5th ed. 1997) (illustrating the ambiguity of perception). Michael Bacharach draws the interesting parallel between the difficulties involved in seeing the two figures in the rabbit-duck diagram and the difficulties in being able, simultaneously, to "frame" a decision problem in two different, but equally relevant, ways. See Michael Bacharach, "We" Equilibria: A Variable Frame Theory of Cooperation (June 10, 1997) (unpublished manuscript, on file with the University of Pennsylvania Law Review).

${ }^{2}$ See Michael Stocker, PluRal ANd Conflicting Values 177 (1990) (explaining that plural values, such as the qualities of two wines, cannot be compared in quantitative terms because their plurality relates to their different natures).

${ }^{3}$ See Cass R. Sunstein, Incommensurability and Valuation in Law, 92 MICH. L. REV. 779,797 (1994) (suggesting that the commensurability assumption does "violence" to the way the different goods are "experienced" by those who value them in some particular way). While this reference to experiential violence sounds more empirical than conceptual, Sunstein also refers to commensurability as being "inconsistent" with our "understanding" of the goods so measured. Id. at 798. Notions of inconsistency and understanding suggest conceptual conflict. 
and subsequent choices between the requirements of the chosen career and those of family life. ${ }^{4}$ It seems wrong to say that these choices are difficult merely because of information problems or because all the relevant considerations are somehow in balance under a single measure of overall value, even one as general as how happy we will be in life. Rather, we can be quite convinced that we will be happier with one career choice than another and still feel puzzled about how to proceed. The greater overall happiness of one career choice does not seem adequate to account for what is at stake. (We might feel some duty to join the family firm, for example, even though we might be happier as an academic.) Or we can estimate that we will be equally happy with either career choice and still feel that we are far from indifference (the natural attitude towards balance) about our choice. ${ }^{5}$ This continued puzzlement in the one case, or lack of indifference in the other, indicates the presence of values that are incommensurable, either with happiness or with each other, and that have not been accounted for in the balancing we have done.

In the face of these sorts of difficulties, one can imagine our scholarship committee proceeding in one of several ways. First, it might simply deny the problem of incommensurability and proceed as if tradeoffs between the different criteria really do make some sense. As already suggested, this seems to misrepresent the nature of the criteria at stake. ${ }^{6}$ Second, it might accept the problem of incommensurability and decide that the only way to proceed is by selecting one of the plural criteria as decisive for who should get an entrance scholarship. One can imagine that the choice of one decisive criterion to the exclusion of all others might be controversial; some committee members will deem financial need to be paramount, others

4 The examples of career and family choices are borrowed from the very interesting analysis of incommensurability provided by JOSEPH RAZ, THE MORALITY OF FREEDOM 345-50 (1986) (discussing constitutive incommensurabilities of parenthood and marriage versus money and job choices).

${ }^{5}$ That our inability to choose is not to be explained by the equal balance of our various concerns, the stuff of indifference, is shown by adding some obvious benefit to one of the options. If such an add-on does not "tip the balance" in favor of that option, then the choice difficulty is more likely to be explained by the incommensurability of the values at stake, and not by the fact that these values are evenly balanced. See $i d$. at 325 (discussing intransitivity as a test for incommensurability). For further related discussion, which also shows how complicated the test can become, see John Broome, Is Incommensurability Vagueness?, in INCOMMENSURABILITY, INCOMPARABILITY, AND PRACTICAL REASON 67, 67-68 (Ruth Chang ed., 1997) (discussing indeterminate comparatives).

${ }^{6}$ See supra note 2 and accompanying text. 
scholarly ability, and still others community service. Although the integration of these different views seems to raise its own problems of incommensurability, the committee could perhaps choose the decisive criterion by majority rule.

However, the second solution to the problem of incommensurability surely would continue to nag. For while it accepts that there is a problem of incommensurability between values, it denies the very presence of plural values, opting instead for an entirely monistic, or single-valued, approach to the choice problem. This suggests a third, slightly different way for the scholarship committee to accommodate the plural criteria that seem genuinely relevant to the choice of scholarship winners. The committee could adopt a lexical ordering of the different criteria, ${ }^{7}$ using the first lexically ordered criterion, for example, financial need, to rank the candidates from first to last, and using a second criterion, for example, scholarly ability, to break any ties that might arise under the primary criterion. The third criterion could likewise break any further ties that might arise under the use of the second. This lexical procedure also would invite controversy, of course, since, again, therè likely will be disagreement amongst the committee members as to the order in which the different criteria should be considered. But the lexical procedure at least has some residual traces of the pluralism with which we began, and handles that pluralism without assuming criterial commensurability.

So far we do not seem to have a very rich array of strategies for dealing with the problem of incommensurability; but, surprisingly, within the conventions of the economic theory of rational choice, there appear to be no more strategic options from which to choose. ${ }^{8}$

${ }^{7}$ A lexical ordering of criteria requires us to satisfy the first principle in the ordering as much as possible before going on to consider the second; the second is used only to break any ties arising out of consideration of the first. Likewise, the second is satisfied before the third, and so on, See JOHN RAWLS, A THEORY OF JUSTICE 43 (1971).

${ }^{8}$ Strictly speaking, there is a third option that does sometimes appear within rational choice theory as a strategy for dealing with incommensurable values. This involves thinking of each of the incommensurable values as being advanced by an agent who bargains on its behalf. The "best compromise" among the different values, then, is a kind of bargaining solution reached by the different agents. As the axiomatizations of the different bargaining solutions reveal, such bargaining need not assume commensurability. Nash's bargaining solution, for example, is invariant with respect to any linear transformation of any one of the numerical representations of the different values; this indicates that his particular solution to the bargaining problem is insensitive to the choice of any common (cardinal) measure of these values. See AMARTYA K. SEN, COLlective CHOICE AND SOCIAL WELFARE 118-30 (1970) (discussing the Nash bargaining solution as a social-choice rule); David Luban, Incommensurable Values, Rational Choice, and Moral Absolutes, 38 CLEV. ST. L. REV. 65, $71-73$ (1990) (using 
Either one is prepared to countenance tradeoffs between qualitatively different criteria in the way that commensurability demands, or one is single-mindedly absolute with respect to one value, allowing secondary values in, at best, only as tie-breakers should the first value fail to be decisive in the way required. In the economist's typical geometrical representation of the space of alternative choices, there are indifference curves either everywhere or nowhere; there is nothing in between. ${ }^{9}$ Confronted with such a stark choice, it is less surprising, perhaps, that the economic theorist has typically rejected the almost

explicitly the Nash solution in the context of incommensurability). Interestingly, however, the Nash bargaining solution is partly defined by the (partition independent) rationality property outlined in the next Part of this Article. See infra note 27 and accompanying text. Thus, it falls prey to the criticisms of that property advanced there. Other bargaining solutions, on the other hand, relax this assumption. See, e.g., Ehud Kalai \& Meir Smorodinsky, Other Solutions to Nash's Bargaining Problem, 43 ECONOMETRICA 513 (1975) (suggesting an alternative axiom that leads to another unique solution to the two-person bargaining problem). Thus, bargaining solutions as such, while providing a natural enough method for the "rational" choice theorist to deal with incommensurable values, appear to span the gap from the conventionally rational to what, on the conventional account, is "irrational." The arguments in this Article might be read in part as providing some support for thinking of the "irrational" bargaining solutions as more reasonable (albeit more partition dependent) than they might have first appeared. See infra note 27 and accompanying text.

${ }^{9}$ In geometric representations of rational choice analysis, indifference curves link points in the space of alternative choices between which a chooser is indifferent. Such indifference typically arises when the chooser deems the loss of some attribute relevant to a choice (in moving from one alternative to another) to be compensated sufficiently by the gain (quite possibly only a very large gain) of some other relevant attribute. Hence, indifference curves (also called equal utility curves) pass through every point in the space and capture the possibility of making tradeoffs between choice criteria, that is, they capture the notion of commensurability. See H.A. JOHN GREEN, CONSUMER THEORY 35-38 (1978) (discussing the continuity of preferences represented by curves). Also, at least for positively valued criteria, indifference curves slope down to the right, this slope representing the "price" in the chooser's mind of trading off the different criteria. See id. at 35. Under the second strategy, discussed in the text, where a single-minded committee uses only one decisive criterion to choose, the indifference curves would be parallel to one another and at right angles to the axis measuring different amounts of that criterion. Finally, under the third strategy, allowing for a lexically ordered consideration of different criteria, there would be no indifference curves at all, since every point in the space of alternatives would be related to every other point by strict preference. (Compare the strict ordering of words in a dictionary; there are no ties. The word "lexical," of course, derives from "lexicographical," where the latter describes the ordering in a dictionary.) Assuming indifference curves can always be drawn amounts to assuming that the chooser's preferences over the alternatives are continuous; where the curves cannot be drawn, as for lexical orderings, the preferences are said to be discontinuous. See id. at 35-38. 
fanatical single-mindedness of absolutism, and embraced the universal possibility of tradeoffs. ${ }^{10}$

In this Article I suggest that there is, in fact, an alternative strategy that is "in between" these two extremes, and that this strategy is manifested, sensibly and regularly, in law and adjudication as a way to accommodate plural values in decisionmaking. I shall eventually refer to this strategy as the method of "conceptually sequenced argument." Although I shall exemplify the particularly legal version of this strategy in the course of this Article, the beginnings of what such a strategy looks like, and how it differs structurally from the other strategies already discussed, can be illustrated by way of the scholarship committee example.

Suppose the committee decides to proceed in the following way: First, it ranks all the scholarship candidates according to financial need. Then, having selected the top ten candidates on that first list, it ranks all of those candidates according to scholarly ability and selects the top five scholars. Then, it ranks these last five according to community service, choosing as its three scholarship winners the top three candidates on the final list.

What I have just described would hardly be a radical proposal for a committee procedure; one easily can imagine that many committees might already proceed in this way. But notice how the procedure combines some of the features of both the criterial tradeoff model and the lexical ordering model without reducing completely to one

${ }^{10}$ Again, the bargaining literature, see supra note 8, suggests a third possibility. One might think of an optimal choice from a set of incommensurable alternatives as that one which is best in its own terms, or on its own scale. For example, this is probably how a judge chooses "the best dog in the show" where very different (incommensurable) breeds of dog compete. The best dog is that one which is closest to the particular ideal as this is set by the different breed standards, and "closest" here refers to how high each dog is, proportionally, on its own breed scale. (To demand commensurability across the different breeds would be analogous to imposing on the competition some super-standard of an "ideal dog," against which each dog, or breed of dog, would be compared and assessed quantitatively; a lexical standard would select some particular breed, or particular characteristic of a breed, as of absolutely prior importance in the show, only going on to "secondary" breeds or characteristics to break ties.) While these proportional comparisons, like the comparisons in Nash's bargaining theory solution, require cardinality, they do not require interscale cardinality or commensurability. Indeed, it is not clear in what sense they even require any interscale comparability. Certainly, there is nothing like Ruth Chang's overarching "choice value" in operation here, except in the trivial sense that, after the choice is made, the judge will have chosen "the best dog in the show." For the argument that choice requires comparability or choice value, see Ruth Chang, Comparison and the Justification of Choice, 146 U. PA. L. REV. 1569 (1998). 
or the other. On the one hand, the lexical ordering notion (no tradeoff) is preserved in the idea that the different criteria have a sequenced priority with respect to one another; if financial need is the first priority in the scheme, no candidate having very high scholarly abilities but no real financial need (in other words, someone so low on the first list as not to make the first cut) will be chosen by the procedure under any circumstances. Very high scholarly ability is never allowed to "compensate" for low financial need since, under this scheme, the committee never makes such a comparison. On the other hand, under the scheme the prior financial need criterion is subject to an override by the secondary criterion of scholarly ability, at least for those candidates selected for the first list on the basis of financial need. Thus, candidates on the first list who have more financial need (that is, more of the primary criterion) may not receive a scholarship because they are trumped by those on the second or third list who have more scholarly ability or community service. In this way, the scheme allows the secondary and tertiary criteria to do more than merely break ties generated by the first criterion, the role they would have played within a lexically ordered application. Rather, in a limited, sequenced sense, the committee balances between, or makes a joint accommodation of, the different criteria, although it never actually has to balance the criteria for any particular pair of candidates. ${ }^{11}$

Of course, there are problems with this sort of decision procedure, not least of which is the political one that the sequence of consideration of the different criteria still will be controversial. Different sequences will often determine different final outcomes. Thus, one objection goes, the procedure simply substitutes an indirect controversy over the sequencing of procedures for the original more direct and candid controversy about the outcomes themselves. ${ }^{12}$

"It will be objected that the balancing is done implicitly when the committee chooses the "cutoff" point for each of the lists at each of the three stages of choice. While there may be something to this objection in general, this Article will show that schemes with this structure need not be ordered this way at all. Rather than being ordered by tradeoffs, the transitions between the different criteria might be "conceptually ordered" at each stage. On this, see infra Part II. Also, even if the cutoff point somehow is priced as a tradeoff between the two criteria in question at that point of the procedure, it remains true that there is no attempt in this procedure to effect price-like comparisons for all possible pairs of alternatives with respect to the two criteria. Thus, even if it could be argued that there is some form of commensurability here, there is not full commensurability, or commensurability with unlimited reach into all possible partitions of the available alternatives.

${ }^{12}$ This would be the view of the public choice theorist. Essentially, what I propose is what the public choice theorist would call a "structure-induced equilibrium," where, 
Another objection is that there may be something normatively incoherent in this procedure, since it asserts the priority of one value at one stage of the procedure, only to have that priority contradicted or denied by a supposedly nonprior (or secondary) value at the second stage. Which value, the normative question will go, really is the prior one in such a normative system ${ }^{13}$

The point of outlining such a structurally different procedure at this point in the Article is not to defend it in any detail, but only to suggest that there are methods for dealing with pluralism other than those conventionally assumed by rational choice theory, commensurability, or lexical ordering. Moreover, both the political and the normative objections to the proposed procedure assume that the particular sequence used to apply the different criteria is a matter of discretionary choice. The political objection assumes, for example, that the different criteria can be just as easily arranged in one order as in the next. This objection is, admittedly, suggested by the scholarship committee hypothetical, but it might not be true generally. Under different descriptions of a choice problem, some criterial sequences may simply "make more sense" than others; not all choice sequences, therefore, are equally easy to support politically, at least if the supporters have to offer publicly accessible reasons for their preferred choice sequence. Indeed, the idea that different values, as introduced into an overall all-things-considered decision, might be "conceptually sequenced" rather than arbitrary will be a central theme of this Article. The argument will be that legal decisionmaking, which emphasizes choice based on reasons, makes use of this

to avoid the disequilibria of multidimensional choice, politically decisive coalitions (usually assumed to be majorities) consider the different dimensions of choice (or choice criteria) one at a time, or issue by issue. For a good discussion of this idea, see Gerald S. STROM, THE LogIC OF LAWMAKING 92-113 (1990). This system is stable because no one may propose an alternative that changes the status quo on two such dimensions simultaneously. The difficulty is that, in general, the particular outcome that will be selected under any given agenda, or set of issues, is predictable. Thus, the public choice theorist worries that political conflict now will shift, just as predictably, from a focused consideration of the alternatives themselves to a debate over what particular issues should be allowed to constitute the agenda leading to a particular equilibrium outcome. For a good discussion of the broad range of possibilities under such "agenda influence," see Michael E. Levine \& Charles R. Plott, Agenda Influence and Its Implications, 63 VA. L. REV. 561 (1977), and Richard D. McKelvey, Intransitivities in Multidimensional Voting Models and Some Implications for Agenda Control, 12 J. ECON. THEORY 472 (1976).

${ }^{13}$ Ernest Weinrib's criticisms of George Fletcher's notion of "structured" legal thinking are similar to this. For discussion of Weinrib and Fletcher, see infra note 68 and accompanying text. 
idea in a way that is instructive for the theory of rational choice and the sensible accommodation of plural criteria. ${ }^{14}$

The idea of a conceptually sequenced ordering of criteria might also provide the basis for a response to the normative objection that there is a kind of incoherence in asserting the priority of one value at one stage of the procedure while allowing that priority to be denied or contradicted at a subsequent stage. A conceptually sequenced argument might provide a quite different sort of ordering for decisionmaking from that provided by a value ordering. A procedure that appears contradictory if we look at the choices as revealing only underlying values might be perfectly coherent if we understand it as ordered by concepts.

Indeed, in Part II of this Article, which introduces the idea of reason-based choice, I will demonstrate that this is so. In particular, Part II will show how reason-based choice can depend on which particular partition of an overall set of alternatives has been made available for choice at any given point in a choice process. Partitions of the alternatives may be different because some alternatives have been added to or subtracted from those originally available for choice. They can put different matters "at issue," and call for quite different choices, even amongst those alternatives that originally were available. I will argue that this sort of partition-dependent choice, while perfectly sensible, is inconsistent with the usual requirements of rational choice theory, which are conventionally based on maximization of some overall ordering of values.

When I have shown that reason-based choice is structurally different from the value orderings assumed by the normative incoherence objection specifically, and by rational choice theory more generally, one can better appreciate how the rationality of law and adjudication, which is based so self-consciously on sequenced argument and the obligation to provide reasons, nonetheless differs in a useful and interesting way from the rationality assumed by the economic theory of rational choice. In Part III, therefore, I will provide some legal examples of a conceptually sequenced accommodation of plural criteria. I

${ }^{14}$ I have argued elsewhere that both a conceptually sequenced argument and an obligation to give reasons may provide relief from some of the systematic difficulties encountered in the theory of social choice. See Bruce Chapman, More Easily Done Than Said: Rules, Reasons, and Rational Social Choice, 18 OXFORD J. LEGAL STUD. (forthcoming 1998) [hereinafter Chapman, More Easily Done Than Said]; Bruce Chapman, Pluralism in Tort and Accident Law: Towards a Reasonable Accommodation, in PHILOSOPHY AND THE LAW OF TORTS (Gerald J. Postema ed., forthcoming 1998). 
will end with some concluding remarks about how a reasonable person conducts an argument in Part IV.

\section{REASON-BASED CHOICE AS AN ALTERNATE FORM OF ORDERING}

It is tempting to think that the attributes of each of the available alternatives are all that is relevant for choice. Furthermore, we might think that the alternative that we have most reason to choose, all things considered, is the alternative that is the best of those available as measured by those attributes. In this sense, therefore, rational choice reduces to the maximization of the value or values we see in the alternatives for choice. Crudely, we might say that reason and rationality should track the good in choosing, and "most reason" would identify the most good in, or the "best" of, the things that might be chosen.

However, some recent behavioral research on reason-based choice suggests that reasons for choice can lead individuals to choose in a way that violates the logic of "good, better, and best"-that is, the value-maximizing logic on which rational choice is typically thought to depend. ${ }^{15}$ For example, adding an alternative to an individual's set of available alternatives that is dominated (in other words, worse according to all relevant criteria for choice) by another previously available alternative can make it more likely that the individual will choose the dominant alternative over a third alternative (not so dominated) that was also previously available. Yet it is hard to see, at least according to rational choice theory, focused as it is on the unchanging attributes of the alternatives for choice, why the relative value or good of two alternatives should be influenced by adding a third option to the opportunity set. Indeed, it is axiomatic within the economic theory of rational choice that, since the relative value or good of two alternatives is not so influenced, choice between two alternatives $x$ and $y$ should not change (or should be consistent) when other alternatives are added to or subtracted from the set of alternatives. This choiceconsistency condition is referred to as the "weak axiom of revealed preference. ${ }^{16}$

${ }^{15}$ See Eldar Shafir et al., Reason-Based Choice, in REASONING AND DECISION MAKING 11-36 (P.N. Johnson-Laird \& Eldar Shafir eds., 1993) (exploring the logic of reasonbased choice and testing some specific hypotheses concerning the role of reasons in decisionmaking).

${ }^{16}$ See Kenneth J. Arrow, Rational Choice Functions and Orderings, 26 ECONOMICA 121, 123 (1959) (providing a precise definition of the "Weak Axiom of Revealed Preference" and showing its logical relationship to other rationality axioms); Georges 
The explanation typically offered for this systematic violation of a choice consistency condition has been that the addition of the third asymmetrically dominated alternative provides a reason for choosing the dominant alternative that did not exist before the addition of the third alternative. Thus, even though nothing in this new reason changes the attributes and, therefore, the comparative worth of the two previously available alternatives, there is now, apparently, "more reason" to choose the dominant alternative from the overall opportunity set. Furthermore, the effects of this asymmetric dominance are apparently enhanced if the choosers anticipate having to justify their decisions to others. ${ }^{17}$

The general tenor of the literature documenting these reasonbased effects on choice is that there is something irrational in them. ${ }^{18}$ And, of course, there is, at least if one holds tight to rationality as it is defined by the theory of rational choice. It is as if we need only take these poor, deluded experimental subjects in hand for a moment and show them the compelling logic of value maximization. Then they would see the error of their reason-based choices.

But there are also grounds for thinking that these experimental results reveal that the theory of rational choice and value maximization provides only a very partial or incomplete understanding of rationality as reason-based choice. It is true that it is odd to latch onto just any new reason as providing "more reason" for choosing alternative $x$ rather than alternative $y$, particularly if the new reason seems relevant only to the dominance of $x$ over some (irrelevant) alternative $z$, and is not at all relevant to the comparative worth of $x$ and $y$ themselves. ${ }^{19}$ Nevertheless, it is easy to think of situations where a different

Bordes, Consistency, Rationality and Collective Choice, 43 REv. ECON. STUD. 451, 453 (1976) (discussing the same, but focusing on social choice theory).

17 See Shafir et al., supra note 15, at 26 (explaining the manner in which test subjects' choices were influenced by dominating alternatives and by third-party review of the choices made) (citing Itamar Simonson, Choice Based on Reasons: The Case of Attraction and Compromise Effects, 16 J. CONSUMER RES. 158 (1989)).

${ }^{18}$ See, for example, id. at 34, noting that

it has been repeatedly observed that the axioms of rational choice which are often violated in non-transparent situations are generally satisfied when their application is transparent. These results suggest that the axioms of rational choice act as compelling arguments, or reasons, for making a particular decision when their applicability has been detected, not as universal laws that constrain people's choices.

Id. at 34 (citation omitted).

${ }^{19}$ It is sometimes explicitly postulated that rational choice should be "independent of irrelevant alternatives" in this way. See, for example, the axiomatization of the Nash bargaining solution in the theory of cooperative games presented in 
partitioning of the set of available alternatives (different because some alternatives have been added to, or subtracted from, the opportunity set, or both) might have the effect of putting quite different matters "at issue" and, therefore, of calling for a quite different sort of choice, a choice that might even vary with respect to previously available alternatives.

Consider the following example. ${ }^{20}$ Someone is about to be offered fruit at a dinner party. If offered a small apple and an orange, she would choose the orange. If offered a large apple and the orange, she would choose the large apple. This seems to reveal that she values the orange more than the small apple and the large apple more than the orange; value maximization surely (and transitivity of her preferences even more surely) would now have her choose the large over the small apple. ${ }^{21}$ Yet, given the choice between the large and the small apple, concerns about proper etiquette at a dinner party might induce her to choose the small apple, an apparent violation of transitivity, at least if choices reveal ordered preferences in the way usually assumed by rational choice theory. Likewise, given a

R. DUNCAN LUCE \& HOWARD RAIFFA, GAMES AND DECISIONS 127 (1957), and in Luban, supra note 8 , at 72 . Unfortunately, the same phrasing has been used to capture a quite different idea in the social-choice literature, and in particular as one of the conditions in the proof of Arrow's impossibility theorem. See KENNETH J. ARROW, SOCIAL CHOICE AND INDIVIDUAL. VALUES 26-28 (2d ed. 1963) (discussing the condition of the independence of irrelevant alternatives). For some clear exposition that Arrow's "independence of irrelevant alternatives" condition is not the same as the axiom of rationality that sometimes appears under the same name, see Paramesh Ray, Independence of Irrelevant Alternatives, 41 ECONOMETRICA 987 (1973). See also SEN, supra note 8, at $17 \mathrm{n} .9$ (explaining that the condition of independence of irrelevant alternatives should not be confused with Arrow's condition of the same name); Amartya Sen, On Weights and Measures: Informational Constraints in Social Welfare Analysis, 45 ECONOMETRICA 1539, 1563 \& n.34 (1977) (noting confusion between the definitions of independence of irrelevant alternatives).

${ }^{20}$ I borrow this example from Paul Anand, The Philosophy of Intransitive Preference, 103 ECON. J. 337, 344 (1993). A similarly structured example involving, on the one hand, forward-looking concerns for the achievement of some social good and, on the other hand, a more backward-looking respect for the requirements of corrective justice can be found in James F. Reynolds \& David C. Paris, The Concept of "Choice" and Arrow's Theorem, 89 ETHICS 354, 363 (1979). Comparable examples, making similar points, are developed in ISAAC LEVI, HARD CHOICES 105 (1986), which puts forth an example using test scores for three job applicants to support the point that revealed preference fails to satisfy the acyclicity condition.

${ }^{21}$ Rational preferences are usually thought to be transitive; thus, if alternative $x$ is (revealed) preferred to alternative $y$, and alternative $y$ is (revealed) preferred to alternative $z$, then alternative $x$ should be (revealed) preferred to alternative $z$ See AMARTYA SEN, Behaviour and the Concept of Preference, in CHOICE, WELFARE AND MEASUREMENT 54, 58 (1982). 
choice of all three fruits (the orange and the big and small apples), she might choose the orange rather than the big apple, deeming that the same concerns about proper etiquette make it impossible for her properly (all things considered) to choose (hedonistically) her most valued piece of fruit. But this combination of, first, choosing the orange over the big apple from the triple (in other words, when the small apple is present and the rule of etiquette against choosing "large" over "small" is at issue) and, second, choosing the big apple over the orange from that pair of alternatives (in other words, when the small apple is not present and this rule of etiquette is not at issue) is precisely the same sort of partition-dependent effect (an effect of adding alternatives to or subtracting alternatives from the opportunity set) that we alluded to above as so problematic for the theory of rational choice. ${ }^{22}$

Yet this example suggests that such "issue-dependent" choice can hardly be deemed irrational as a general matter. Even after close examination of the choices in this situation, ${ }^{23}$ the relevance of etiquette as an issue sensibly seems to persist for some of the partitions of the three alternatives (namely those with both apples available for choice), providing a perfectly sensible reason for not choosing the big apple in those partitions, however much one might otherwise be tempted to choose it. That such partition- or issue-dependent choice is at variance with the choice consistency requirements of rational choice theory is certainly worthy of our notice, but, without more being said, there is little in the bare fact of this conflict that argues that we resolve it in favor of those special rationality requirements rather than some other account of reason-based choice.

It is also worth emphasizing that the intransitivity or choice inconsistency in this example is not the consequence of assigning etiquette some lexically absolute value over the more purely hedonic pleasure of consuming large pieces of fruit. It is quite possible that a polite chooser might be permitted to let hedonism trump etiquette at some point-for example, where it is too much to expect a reasonable chooser to resist the gap in pleasure between the big and small apples. In such a situation, of course, where hedonism becomes the

${ }^{22}$ What is violated here, of course, is the weak axiom of revealed preference, the choice-theoretic equivalent of a fully transitive preference ordering. See Arrow, supra note 16, at 125 (proving this equivalence in Theorem 3); Amartya K. Sen, Choice Functions and Revealed Preference, 38 REV. ECON. STUD. 307, $310-12$ (1971) (showing this same equivalence as well as others).

${ }^{23}$ See supra note 18 and accompanying text. 
one value that is everywhere decisive for what is chosen, the chooser would behave in a way consistent with the usual requirements of rational choice.

These characteristics are reminiscent of our general goal of finding some middle ground between, on the one hand, assuming full commensurability between plural values and, on the other, imposing absolute, lexical priorities on them. Thus, reason-based choice can have the following two characteristics, at least as illustrated by the etiquette example. First, under reason-based choice, a reason $R$ can have a partition-dependent effect on choice, such that $R$ will be decisive for some partitions of the alternatives and yet completely irrelevant to others. In the dinner party example, the rule of etiquette "Do not choose the larger of two items of the same kind" was relevant only to partitions with the two apples and was not relevant to the other choice partitions at all. It is this "on-off" or threshold character of reason-based choice with respect to particular partitions of the alternatives that can generate the possibility of an intransitivity or inconsistency in a chooser's revealed preferences. This categorical nature of reason-based choice also brings it closer to the qualitative differences that are characteristic of pluralism and lexical orderings.

However, the second characteristic of reason-based choice, as already discussed, just as quickly takes us away from the absolute priorities of lexical orderings. Reason $R$ might be irrelevant to some partitions of the alternatives, which are governed exclusively by consideration $W$, and be decisive up to a point for others, say, for partitions of type $X$; nevertheless, beyond that point in $X$, it might be that consideration $W$ (perhaps always present in $X$ ) will trump reason $R$. It is this possibility, namely the essentially monistic one that allows tradeoffs under consideration $W$ ultimately to be decisive for all partitions of the alternatives, type $X$ included, that holds out the possibility of restoring transitivity and choice consistency in the way conventionally assumed by rational choice theory. Rational choice theory errs, however, in mistaking this particular case for the whole range of possibilities.

Of course, introducing a tradeoff possibility anywhere seems to open the door to the economist's familiar indifference curve analysis. However, just as it would be a mistake to assume that reason $R$ must reign absolute over the partitions $X$ of alternatives that are relevant to it, never giving way to any considerations $W$, it also would be wrong to think that, because there is a tradeoff somewhere between $R$ and $W$, there has to be such a tradeoff possible everywhere in $X$, that is, for all 
possible partitions of type $X$ That would be to forget the truly pluralistic and categorically different nature of $R$, converting its relation to $W$ in $X$ into one that is more characteristic of a "price." Thus, while $R$ need not be absolute or "priceless" in $X$ with respect to consideration $W, R$ may not always have an appropriate price in terms of $W$ either. Again, there is the elusive middle between "prices nowhere" and "prices everywhere." As the etiquette example illustrates, a normative concept can apply to a choice problem (or partition $X$ of alternatives) or not. That is, it can apply categorically and completely determine choice (in other words, without any attention to $W$ ), and it can also at some point yield its determinative application on type $X$ partitions to the categorically different consideration $W$ if the stakes with respect to $W$ get too large. The first possibility threatens "rationality," at least as this is narrowly understood by rational choice theory to require preference transitivity or choice consistency; the second possibility restores rationality. Both are legitimate and sensible possibilities.

So far in this discussion we have been challenging the idea, implicit in much of rational choice theory, that reasons for choice are found only in the various attributes that are possessed, individually, by the different alternatives available for choice. On this view, the alternative that we would have the most reason to choose is the one with the most of whatever attribute we consider particularly attractive or compelling. Obviously, if we are going to avoid embarrassing intransitivities of preference, the sort of thing that would make value or preference maximization impossible, ${ }^{24}$ we must either find a single decisive attribute within each alternative for choice (and order the alternatives transitively according to the quantitative variation of that attribute in each alternative) or we must admit that the alternatives might vary in the attributes they possess (and order the alternatives transitively according to the order in which we consider these attributes to be differentially compelling). The first strategy is (singlevalued) monism or, at most, commensurability of plural values under a single organizing metric; the second is the imposition of lexical priorities on plural values. Thus, given the idea of value or preference

${ }^{24}$ If preferences or values are intransitive or, more specifically, cyclical, such that alternative $x$ is preferred to (or more valuable than) alternative $y$, alternative $y$ is preferred to (or more valuable than) alternative $z$, but alternative $z$ is preferred to (or more valuable than) alternative $x$, then it is not possible to choose any one of these three alternatives such that there is no alternative that is not more preferred to (or more valuable than) the one chosen. That is, it is not possible to maximize one's preferences (or values). 
maximization and the logic of transitivity that this idea appears to require, it should not be surprising that rational choice theorists, wedded to that logic, have restricted their gaze to these two rather limited strategies for dealing with pluralism.

The idea of reason-based choice, however, has introduced the thought that choices can sensibly be "ordered" by the relationships that exist between alternatives (even mutually exclusive alternatives ${ }^{25}$ ), and not just by the attributes of alternatives considered individually. Indeed, this relational idea was present, albeit in a not very compelling form, even in the somewhat odd etiquette example, where adding a dominated alternative provided a new reason to choose the (now) dominant alternative over a previously available alternative that was not so dominated. Dominance, after all, is not a property of any individual alternative; rather, it is a relationship that holds between alternatives. The problem with the earlier example was that the new dominance relationship seemed to affect choice between alternatives that were not in any way a part of that relationship. More secure is the general notion that some alternatives can combine to put certain matters, or normative concepts, "at issue," as in the etiquette example. This notion calls for the sort of partition-dependent choice that violates both preference transitivity and the logic of value maximiza-

${ }^{25}$ It may seem odd to think about relationships that exist between alternatives if the alternatives are "mutually exclusive," that is, if they cannot exist together. The choice of one precludes the choice of the other. Indeed, Paul Samuelson has made use of this seeming oddity to make an analogous argument for his "independence axiom," a rationality requirement found in expected utility theory, the theory of rational choice that deals with situations involving risk. See Paul A. Samuelson, Probability, Utility, and the Independence Axiom, 20 ECONOMETRICA 670, 672-73 (1952) (discussing mutually exclusive alternatives, the "independence axiom," and the maximization of expected cardinal utility). Because, under risk, the different possible social states represent mutually exclusive possible outcomes, Samuelson has argued that it is reasonable to ignore any interactive effects between these social states in the way assumed by the independence axiom. Interestingly, criticisms of this independence axiom turn on the fact that choosers react to "nonseparable" features of the lotteries that they face; in other words, features of the lottery as a whole rather than of any one of the possible social states taken separately. This is, for example, the basis of the "certainty preference" in Allais's paradox. See Maurice Allais, The Foundations of a Positive Theory of Choice Involving Risk and a Criticism of the Postulates and Axioms of the American Schooh in EXPECTED UTILITY HYPOTHESIS AND THE ALLAIS PARADOX 27, 86-95 (Maurice Allais \& Ole Hagen eds., 1979). The certainty (attractive to some) of getting some given payoff in every possible state of nature (or social state) is not a property of any one state of nature; rather, it is a property of all the (mutually exclusive) alternative social states as a whole; that is, it is a property of their relationship. Here I argue for the same sort of sensitivity to relationships that might exist between (even) mutually exclusive alternatives for choice. 
tion that depends so much upon it. Additionally, once we have a sensible notion of partition-dependent choice in place, we are also at liberty, in a way that the rational choice theorist is not, to seek out quite different strategies for dealing with plural and incommensurable values.

It might be objected, however, that the very idea of partition dependence, introduced here as a way to make sense of plural considerations in choice, can also be used to avoid the difficulties of pluralism altogether. At the dinner party, for instance, we can make an end run around the whole issue of etiquette simply by never presenting those choice partitions that put etiquette at issue to the chooser. Let her choose first, for example, between the orange, $O$, and the small apple, $a$; she will choose the orange. Then let her choose between the orange and the large apple, $A$, and she will choose the large apple. Having then had a look at all the available alternatives in the choice sequence "First $(O, a)$, then $(A, O)$, , the choice problem might reasonably be brought to a close, with questions of etiquette-and the apparent dangers of "irrationality" that accompany it-completely avoided. Or so the argument might go.

Avoiding these apparent dangers by avoiding the relevant choice partitions also, unfortunately, appears to avoid what may really be at issue. We had a similar reaction earlier when our scholarship committee tried to change a pluralistic choice problem into a monistic one by focusing on only one of the scholarship selection criteria to the exclusion of two others that seemed genuinely relevant to what was at stake. We may feel that there is less danger of this happening in the dinner party example than in the scholarship example. It is interesting to speculate, however, that this may be explained more by the particular example than anything else. We may thus want to consider, more generally, what might follow from thinking that a fair representation of the choice problem should include a choice partition where etiquette is at issue, that is, where choice partitions including both of the alternatives $A$ and $a$ are presented to the chooser.

Two possible choice sequences immediately spring to mind. The chooser could be presented with the choice sequence "First $(A, a)$, then $(a, O)$," and end up choosing $O$, or be presented with the choice sequence "First $(A, O)$, then $(A, a)$," and end up choosing $a$. Both of these choice sequences preserve etiquette as an issue, although the former puts it at issue first in the sequence and the latter puts it second. The order affects the final choice. Is there any reason to choose one of these choice sequences rather than the other? There does not 
seem to be any obvious reason to make etiquette the prior issue here. Consideration of the one other choice sequence that maintains etiquette as an issue, however, suggests that there may be something "more sensible" about the first choice sequence.

The other choice sequence that preserves etiquette as an issue is, of course, the one that presents all the alternatives to our chooser at once; that is, the degenerate single-stage sequence that simply presents the chooser with the one partition $(A, a, O)$. Confronted with such a choice, the chooser likely will break the choice down into the relevant issues anyway, testing choice against what both etiquette and hedonism seem to require. She might reason, for example, as follows: "Etiquette precludes me from choosing $A$ in the presence of $a$, so I might as well do as well as I otherwise can hedonistically and choose $O$." This form of reasoning, which puts etiquette forward as a prior constraint on hedonistic choice, essentially reproduces, in deliberative form, the temporally structured choice sequence "First $(A, a)$, then $(a, O) . "$

Are there any deliberative forms of reasoning over the partition of all three alternatives that are analogous to the second choice sequence referred to above, "First $(A, O)$, then $(A, a)$ "? One can imagine some, but they seem more difficult to construct sensibly. The chooser might reason, for example, as follows: "On purely hedonistic grounds I would prefer $A$ to $O$, but I cannot choose $A$ in the presence of $a$ as a matter of etiquette, so I will settle on $a$ instead." Or perhaps the reasoning might be: "Hedonism precludes me from choosing $O$ rather than $A$, but as between $A$ and $a$, I must choose $a$ as a matter of etiquette." However, both of these interpretations of possible sequences of reasoning seem strained. The first pays a kind of lip service to hedonism in its first breath, but (somewhat myopically) allows etiquette almost immediately in the next breath to gut hedonism of any real purchase on the choice problem. In a sense, this interpretation reduces the problem of plural choice to a problem of monistic choice where etiquette reigns supreme. The second interpretation of a possible sequence of reasoning seems to commit the reverse sort of error, although it gets the poor chooser to the same unhappy result. Now hedonism is advanced first in a very hard-nosed way, as a deliberative trump on the very possibility of choosing $O$, something that has the effect (like the proverbial unbending reed before a prevailing wind) of exposing the only remaining hedonistic choice to the relentless effect of etiquette at the second deliberative moment. This may appear more pluralistic than the first interpretation of how to reason 
to the choice of $a$ from the three alternatives, but its completely unaccommodating-we are tempted even to say "uncoordinated" or "incoherent" ${ }^{\prime 26}$-application of the two criteria seems to undermine a genuinely pluralistic choice just as much in the end.

Therefore, if we want to preserve not only the formal, but also the sensible, possibility of pluralistic choice in the dinner party example, we seem driven to present the chooser either with the explicitly (and temporally) structured choice sequence "First $(A, a)$, then $(a, O)$," or with the whole partition $(A, a, O)$, a partition that will, on any sensible interpretation, be broken down into a deliberative version of the explicitly structured choice sequence in any case. Thus, sensible pluralistic choice is not only partition-dependent in that it must present the chooser with certain partitions such as $(A, a)$ in order to respect the categorically distinct nature of the plural considerations, but also path-dependent in that it must present these partitions to the chooser in a certain order. ${ }^{27}$ Pluralistic choice, therefore, not only is conceptually ordered, but also is conceptually sequenced. ${ }^{28}$

${ }^{26}$ For an interesting suggestion that both the intrapersonal problem of deliberative choice and the interpersonal problem of cooperative choice involve the same problem of coordination, see Edward F. McClennen, Pragmatic Rationality and Rules, 26 PHIL. \& PUB. AFF. 210, 217-22, 243-51 (1997).

${ }^{27}$ The idea of path dependence was first introduced into the rational choice literature by Kenneth Arrow. See ARROW, supra note 19, at 120 . The reverse of the idea, path independence, is discussed much more fully in Charles Plott, Path Independence, Rationality, and Social Choice, 41 ECONOMETRICA 1075 (1973). According to Plott:

[T] he process of choosing, from a dynamic point of view, frequently proceeds in a type of "divide and conquer" manner. The alternatives are "split up" into smaller sets, a choice is made over each of these sets, the chosen elements are collected, and then a choice is made from them. Path independence, in this case, would mean that the final result would be independent of the way the alternatives were initially divided up for consideration.

Id. at 1079-80. Arrow's view was that social choices should not be path dependent since rational choices should be made on the basis of the characteristics of the alternatives themselves and not according to some arbitrary order in which the alternatives are presented to the chooser. However, as the discussion in the text should suggest, if some choice sequences are conceptually ordered, or make more sense than others, then the choices resulting from their use need not be arbitrary in the way Arrow feared. This Article can be viewed as an attempt to argue for the existence of nonarbitrary path-dependent choice by way of conceptually sequenced argument.

${ }_{23}$ For further argument that rational social choice might require privileged choice paths, rather than merely privileged choice partitions, see Chapman, More Easily Done Than Said, supra note 14 (using the example of a criminal trial to illustrate the preferability of certain choice paths), and Bruce Chapman \& Michael Trebilcock, Making Hard Social Choices: Lessons from the Auto Accident Compensation Debate, 44 RUTGERS L. REv. 797, 851-62 (1992) (appealing to institutional concerns and conceptual priorities to identify the preferred choice sequence for choosing an accident-compensation scheme). 
Before showing how conceptually sequenced argument brings order to pluralistic choice in law, it might be useful to summarize the argument in the Article to this point. I have attempted to find some middle ground between, on the one hand, assuming that plural values are always commensurable, which seems to deny the genuinely distinct nature of plural values, and, on the other hand, assuming that plural values have to be lexically ordered with respect to one another, which seems to commit the chooser to an overly extreme form of absolutism with respect to those values that are thought to be normatively prior in the value ordering. I have argued, with the help of some very simple examples, that this middle ground can be found in the idea of partition- and (more specifically) path-dependent choice. Partition dependence builds on the insight that reason-based choice, and the applicability of concepts used in reason-based choice, are not so much a function of the properties of alternatives considered individually as they are a function of the sorts of relationships that hold between alternatives. Choice between different alternatives tends to put different matters at issue-matters that can so radically affect how a given choice is "framed" that some of the most fundamental choice consistency conditions used in rational choice theory are violated. ${ }^{29}$ Further, partition dependence can, in many situations, more specifically entail path dependence because, of the different choice sequences that make use of the choice partitions privileged by reasonbased choice, some such sequences simply make more sense, or provide for a more coherent, coordinated use of the plural values at stake, than others.

This much of the argument explains how reason-based choice might, quite sensibly, provide for a very differently structured ordering of plural values than that assumed by rational choice theories, in either their fully commensurable or their lexically ordered versions. However, I have also argued that the categorical (or categorically selective) application of certain criteria to particular partitions of alternatives can yield, sensibly, to the application of other more general criteria, at least if the losses in terms of these more general criteria

${ }^{29}$ The idea that choice is subject to so-called "framing" effects is now well supported empirically. See, e.g., Amos Tversky \& Daniel Kahneman, Rational Choice and the Framing of Decisions, 59 J. BuS. S251, S257-70 (Supp. 1986) (discussing framing as an example of the deviation of actual decisionmaking from standard rational choice models). What has been missing in this literature is the idea that variable responses to different frames may (on some interpretations) exhibit rationality rather than be contrary to it. 
become too large. Thus, while categories apply, and even apply categorically (that is, to certain partitions of alternatives and not others), they do not apply absolutely in the way exemplified by a system of lexically ordered values. Rather, to anticipate some of the language of the next Part of this Article, we might say that the categories apply defeasibly. That this, however, is not simply a system of fully commensurable tradeoffs under a different name is indicated by the fact that choice is both partition- and path-dependent and, therefore, not rational according to the conventions of rational choice theory.

In the next Part of the Article, I argue that this structure for the nonabsolute yet categorical application of plural considerations to decisionmaking is exemplified in the law's emphasis on the process of adjudication as sequenced argument. In adjudication, plural values are admitted into an all-things-considered judgment, or decision, in a way that is both conceptually sequenced and defeasible, precisely the two characteristics of a sensible pluralistic choice that I have been arguing for here.

\section{CONCEPTUALLy SEQUENCED ARgUMENT IN THE LAW: THE ORDERED RELEVANCE OF RIGHTS AND WELFARE}

\section{A. Hart and Epstein on Defeasibility}

The peculiarly legal notion of defeasibility mentioned in the previous Part is most closely associated with the work of H.L.A. Hart. ${ }^{30}$ For Hart, defeasibility refers to the characteristic ability of legal concepts to organize the particulars that underlie them only insofar as the concepts go uncorrected in the cases or, more generally, in subsequent legal argument. ${ }^{31}$ But, according to Hart, defeasibility involves more than the idea, traditionally the one emphasized, that legal norms are not absolute, being subject to other offsetting

20 See H.L.A. Hart, The Ascription of Responsibility and Rights, in LOGIC AND LANGUAGE 145 (Antony Flew ed., 1952). For a discussion of the significance of Hart's analysis, see G.P. Baker, Defeasibility and Meaning, in LAW, MORALITY, AND SOCIETY 26 (P.M.S. Hacker \& J. Raz eds., 1977).

${ }^{31}$ For further discussion of this idea within a rational choice framework, see Bruce Chapman, The Rational and the Reasonable: Social Choice Theory and Adjudication, $61 \mathrm{U}$. CHI. L. REV. 41, 49-83 (1994), which describes the constant adjustment of legal rules to changing circumstances. See also Bruce Chapman, Tort Law Reasoning and the Achievement of Good, in TORT THEORY 73, 74-75 (Ken Cooper-Stephenson \& Elaine Gibson eds., 1993) (exploring the conflict, in the application of legal norms, between the general requirements of rules and the particular requirements of specific and highly variable circumstances). 
considerations. That proposition provides only a partial understanding of defeasibility, limiting it to but one of its aspects, the possibility of tradeoffs. For Hart, defeasibility is also an essentially sequenced idea, where the different legal norms, with their offsetting effect, are only admitted into the decisionmaking calculus in a certain order of priority. In this way, Hart's notion of defeasibility captures both the idea of path-dependent choice and the notion of a limited tradeoff, precisely the two aspects of a sensibly structured pluralistic choice for which I have been arguing.

Although he believed that the notion of defeasibility has wide application in the law, Hart developed the idea most explicitly with reference to the concept of a "contract." For Hart, as much as for other legal scholars, a valid contract requires the usual list of positive conditions (that is, at least two parties; an offer by one; its acceptance by the other; and consideration on both sides). Under Hart's analysis, however, knowledge of these conditions does not give a full understanding of the concept of contract. A complete picture also includes some knowledge of the ways in which the claim that there is a valid contract might be defeated. For example, one party might allege fraudulent misrepresentation, duress, or lunacy. Hart suggested that the concept of contract is best explained by setting out a list of conditions that are normally necessary and sufficient for the existence of a valid contract, together with a series of "unless" clauses that spell out the conditions under which this existence claim is defeated.

Now Hart recognized that some theorists show an "obstinate loyalty to the persuasive but misleading logical ideal that all concepts must be capable of definition." ${ }^{32}$ These theorists, he predicted, would be tempted to reduce an "irreducibly defeasible",33 concept to a set of conditions that are always necessary and sufficient for the concept's deployment in particular circumstances. ${ }^{34}$ What Hart had in mind

${ }^{32}$ Hart, supra note 30 , at 152 .

3s Id. at 150.

34 Those who argue that a complete statement of a rule should include a full and detailed articulation of its exceptions exemplify Hart's prediction. See, e.g., RONALD DWORKIN, TAKING RIGHTS SERIOUSLY 25 (1977) (“[A]n accurate statement of [a] rule would take... [its] exception[s] into account, and any that did not would be incomplete."); FREDERICK SCHAUER, PLAYNG BY THE RULES 115-16 (1991) (conceding that "rules may have exceptions and still be rules," but arguing that "rules may [not] be subject to exceptions added at the moment of application in light of the full range of otherwise applicable factors and still be rules"). For an excellent criticism of this account of rules and their exceptions, see Claire Oakes Finkelstein, When the Rule Swallows the Exception, in RULES AND REASONING (Linda Ross Meyer ed., forthcoming 1998). Finkelstein argues effectively that within a plural framework, such as one sometimes 
was the theoretical ploy that would accommodate defeasibility in one step by positing the absence of the defeating conditions as necessary conditions for the concept's proper use.

Hart also recognized, however, that such a reductive move obscures and ultimately misrepresents a legal concept's essentially defeasible nature. As the term's property law origins suggest, a concept is defeasible if (1) it is subject to termination or defeat in the face of certain contingencies, and (2) it remains intact if no such contingencies mature. Stating the absence of the defeating conditions as a necessary condition for the positive application of the concept overlooks the idea in (2) that, until some factual evidence of the defeating conditions is forthcoming, the concept simply does apply to the facts already at hand. In other words, the reductive interpretation of contract, while accommodating the defeating conditions in (1), fails to account for the path-dependent nature of defeasibility that is present in (2).

This path-dependent feature of defeasibility also allows it to make sense of the complicated structure of pleadings and presumptions, as well as shifting burdens of proof, that are characteristic of legal argument in a case, a point that has been eloquently argued by Richard Epstein. ${ }^{35}$ The facts "sufficient" to state a cause of action for the plaintiff are never sufficient in the strictly logical sense that " $P$ is a suf-

finds in the criminal law, it is better to think of exceptions as being external to the rules they qualify. However, in contrast to the analysis of criminal law excuses that is provided infra text accompanying notes 53-74, Finkelstein's analysis of rules and exceptions makes no use of conceptually sequenced argument. For further discussion of the relationship between rules and their independently grounded (or external) exceptions, and the importance that this idea might have for the theory of games, see Bruce Chapman, Law Games: Defeasible Rules and Revisable Rationality, 17 LAW \& PHIL. (forthcoming 1998).

${ }_{35}$ See Richard A. Epstein, Pleadings and Presumptions, 40 U. CHI. L. REv. 556, 559-61 (1973) [hereinafter Epstein, Pleadings] (discussing the application of defeasibility to legal presumptions). Epstein expressly indicates his indebtedness to Hart's earlier work on defeasibility in this paper, but it is arguable that his series of later articles on strict liability and defenses in tort law, while working with the concept of defeasibility less overtly, is, nevertheless, still largely structured around it. For articles in which Epstein adheres to the concept of defeasibility, see, in particular, Richard A. Epstein, $A$ Theory of Strict Liability, 2 J. LEGAL STUD. 151 (1973) (arguing for a prima facie case of liability based on the defendant's causation of harm); Richard A. Epstein, Defenses and Subsequent Pleas in a System of Strict Liability, 3 J. LEGAL STUD. 165, 166-67 (1974) (discussing how subsequent defenses can answer the plaintiff's prima facie case); and Richard A. Epstein, Intentional Harms, 4 J. LEGAL STUD. 391, 394 (1975) (discussing the relevance of the defendant's intention for any defenses advanced by the defendant). 
ficient condition for $Q$. ." In (traditional) logic, ${ }^{36}$ if $P$ is sufficient for $Q$ (or if $P$ implies $Q$ ), then there is no sense in which the sufficiency of $P$ can be undermined by adding further particulars or facts to $P$ (such that, for example, $P$ and $R$ does not imply $Q)$. But that is precisely what the law does allow in a system of pleadings and presumptions. Consider, for instance, one of Epstein's favorite examples of a legally defensible proposition in tort law: A person should be legally responsible to anyone to whom she causes harm. ${ }^{37}$ Stated boldly in this way, the proposition is obviously false. At a minimum, the defenses of consent and self-defense provide exceptions to the proposition as a general rule. ${ }^{38}$ Yet it is not false to assert this proposition in the same way that it would be false, says Epstein, to claim that a person should be held responsible for her evil thoughts about another person. It is tempting to say that the "harm principle," while not conclusive, is at least entitled to a reasonable presumption in law in a way that the analogous "thought principle" is not. And, having secured this presumption, it may require a response, or a defense, if it is not to be conclusive for responsibility against the defendant. It is in this sense that the facts about harm, as proved so far, might be sufficient, whereas the facts about thought never will be. The facts about harm are sufficient, if proved, to complete the plaintiff's prima facie case, but they are insufficient if the plaintiff later has to address (either in the form of a denial or as a confession and avoidance ${ }^{39}$ ) any defenses. But then this simply is the highly structured system of pleadings, presumptions, defenses, and subsequent pleas that is so characteristic of law and legal argument.

${ }^{36}$ The parenthetic qualification is necessary, as formal systems of defeasible or nonmonotonic logic are increasingly available. See, e.g., John L. Pollock, Defeasible Reasoning, 11 COGNITTVE SCI. 481, 481 (1987) (setting forth a logic of defeasible reasoning).

${ }^{37}$ See Epstein, Pleadings, supra note 35, at 558.

ss Epstein's idea that causation, without more, can form a sensible basis for the plaintiff's prima facie case, before one even considers possible defenses, has attracted a good deal of criticism. See, e.g., Stephen R. Perry, The Impossibility of General Strict Liability, 1 CAN. J.L. \& JURIS. 147, 148 (1988) (arguing that mere causation is insuffciently selective as a basis for determining liability in tort law). The point of invoking Epstein's general proposition here, however, is not to defend it in detail, but rather to use it merely as an illustration of a defeasible legal rule.

${ }^{39}$ A denial questions an assertion of fact by the other party, but does not raise any new legal issue. A confession and avoidance admits the truth of the other party's allegations, but argues that a new consideration, consistent with those prior allegations, can defeat the otherwise available inference to the legal result that the other party wishes to establish. 
This characterizes defeasibility as involving a sequenced form of argument. But nothing here yet suggests that this sequence is used in any way to accommodate plural and incommensurable values. Nor is there any reason to think that, even if the sequence is pluralistic, the pluralism is conceptually ordered. As the last Part suggests, we are searching the law for examples of a "conceptually sequenced pluralism," where each one of these three terms has its own special significance. However, the connection between pleadings, presumptions, and defenses within a specifically structured legal argument, and a more general concern for plural values, may not now be so very far away. Indeed, some of Richard Epstein's own work on tort law, at least where it self-consciously attends to the value of individual rights and social welfare, may illustrate the possibilities. However, his may be a sequenced argument that introduces this pluralism without ordering it conceptually.

To see both the possibilities and their limitations, it is useful to consider specifically how Epstein treats the problem of nuisance. ${ }^{40}$ As a rights theorist, Epstein seeks primarily to understand nuisance law through the lens of corrective justice: The plaintiff seeks a remedy against the defendant because the defendant has used her land so as to invade, and thus interfere with, the plaintiff's own legally protected use. Epstein considers this part of his understanding of nuisance, his "point of departure," to be "conceptually ideal." However, certain more practical or administrative matters also must be considered. These Epstein calls "utilitarian constraints," which need to be worked into the substantive law, even if they "demand compromises between principles of utility and principles of justice. ${ }^{42}$ Thus, Epstein's account promises to combine those values that so often are the most salient for social choice-namely, rights and utility. The question for our purposes is whether he does so in a way that makes sense of them in combination, even as it also makes sense of their categorically different (or separate) nature as plural values.

His examples involving interference from, or the blocking of, a neighbor's light are particularly interesting in this respect. Epstein argues that if a defendant neighbor shines light on the plaintiff's land, there is an invasion of that land sufficient for a prima facie case of liability. However, if a defendant merely blocks the light from

${ }^{10}$ See Richard A. Epstein, Nuisance Law: Corrective Justice and Its Utilitarian Constraints, 8 J. LEGAL STUD. 49 (1979).

11 Id. at 50 .

${ }^{42}$ Id. 
reaching the plaintiff's land, there is no such invasion of the plaintiff's legally protected interest and, therefore, no rights violation sufficient to establish a prima facie case for the plaintiff. Thus far the difference between the two cases is explained merely by the applicability or not of Epstein's more general theory of rights violations as involving invasions of some legally protected space. But the next step of Epstein's argument makes the overall structure more plural and complicated. For once the rights violation has been established, the defendant still may introduce utilitarian considerations, including, apparently, the idea that the plaintiff is "extrasensitive" and even that there might be some utilitarian "justification" for tolerating the defendant's invasion. ${ }^{43}$

This sequenced introduction of utilitarian concerns is interesting, whatever one happens to think of the details of Epstein's argument. For the priority of rights to utility is preserved: Utility can be introduced only in a defense to the prima facie case. Thus, the plaintiff whose light was only blocked by the defendant would not, according to Epstein's multistaged analysis, ever be in a position to advance a utilitarian argument for a right to light. There would be no rights invasion in such a case sufficient to put those secondary utilitarian concerns at issue. ${ }^{44}$ However, the plaintiff who has suffered an invasion of light can be subject to the utilitarian defense that such an invasion might be justified. In this way, therefore, Epstein's account of nuisance law exhibits a defeasible ordering of plural values, where individual rights are prior to utility in a path-dependent way, but also subject, at a second stage of the analysis, to defeasance by utilitarian concerns.

So now we have a legal example of a sequenced pluralism that appears to have the very structure we have been seeking. The only

${ }^{43}$ As one might expect, once the plaintiff has proved her prima facie case, Epstein is uncomfortable with introducing the utilitarian thought that "the extrasensitivity defense may rest upon the belief that the efficiency losses of the corrective justice position are simply too great" to allow the plaintiff to prevail. Id. at 92.

14 See id. at 61 ("With the blocking of light, however, there can be no actionability under the invasion test."). And, of course, without actionability at all, there is no subsequent room for a utilitarian "defense." While Epstein devotes most of his analysis to "how utilitarian constraints have worked to remove from the legal system some physical invasions that are in principle actionable under the nuisance principles of corrective justice," he also admits the possibility of the converse situation "where the same utilitarian constraints support the creation of nuisance-like actions even in the complete absence of a physical invasion." Id. at 94 (emphases added). However, Epstein explicitly rejects the latter possibility in the nuisance cases involving light when he considers the utilitarian benefit of solar energy. 
remaining question is whether this sequenced pluralism is conceptually ordered. If it is not, then the problem arises as to why this order, or path, is to be privileged through the pluralism. Why not (to reverse the order in Epstein's title) "Utilitarianism and its Corrective Justice Constraints"?

Surprisingly, Epstein has very little to say as a general matter on this point, and what he does say serves more to confuse than clarify the argument. He does identify two general approaches for bringing in affirmative defenses. In the first, the existence of the defenses "allows the introduction of the vast array of utilitarian considerations that were systematically excluded from the prima facie case." ${ }^{45}$ In the second, the defenses "present the opportunity to take into account the plaintiff's conduct, to determine whether it requires the forfeiture of actions that were otherwise maintainable." He then argues that the first of these is unacceptable, while the second is logically required:

The first view is unacceptable because it renders trivial the aims and purposes of a theory of corrective justice. The point of that theory is not simply to organize the pleadings of particular cases but rather to insure that a single conception-that the antecedent conduct (promises, acts) by one party towards another is the sole source of their relative rights and duties-governs the entire body of tort law. Introducing utilitarian arguments as affirmative defenses undermines this point of view by allowing the calculus of costs and benefits to carry the day, if only at the second stage of the case. Taking into account the plaintiff's conduct, and judging it by the same standards applicable to the defendant's conduct, however, does not compromise the system. Instead it implies the same corrective justice principles in uniform fashion to both parties.

Epstein's position here is confusing, at least as his argument has been characterized so far. First, it seems to fail to appreciate the full effect of a defeasibly structured accommodation of plural values. If a second-order value, like utility, can only come in by way of second-stage affirmative defenses, then "the calculus of costs and benefits" is accordingly circumscribed and cannot, as Epstein suggests, simply "carry the day" as if it were a first-order value. Furthermore, the firstorder aims and purposes of corrective justice are not, as Epstein suggests, rendered "trivial" because they are qualified by social utility. Rather, consistent with genuine pluralism, they are merely inconclu-

\footnotetext{
${ }^{45}$ Id. at 69.

${ }^{46} I d$.

${ }^{47} I d$.
} 
sive. Second, Epstein's call for "a single conception" or "same standards" to govern "the entire body of tort law" is also puzzling. By his own account, ${ }^{48}$ the whole point of the nuisance law paper was to harmonize two different values, rights and utility. One has to wonder why, at one point in Epstein's analysis, this pluralism can be admitted somehow as a genuine problem to be reckoned with, while, at some other point, it provides grounds for dismissing a given approach to the problem because the approach involves unacceptably diverse standards. Perhaps what Epstein means to worry about is not so much the diversity of plural values in general, but rather the more particular idea that not just any sort of pluralism can be conceptually ordered or sequenced. We now turn to a more explicit discussion of a conceptually sequenced pluralism of rights and welfare.

\section{B. Fletcher on Structured Legal Reasoning}

George Fletcher is another legal theorist whose work emphasizes the sequenced accommodation of plural values, in particular, rights and welfare. ${ }^{49}$ In contrast to Epstein, Fletcher is more aware that this sequenced structure needs to be, and often is, conceptually ordered. This conceptual ordering is best exemplified in the essential role

${ }^{18}$ Epstein offers the following characterization of his argument:

The root of the problem therefore is that there is no common coinage between the language of rights and wrongs and the language of costs and benefits. Indeed all that can be shown conclusively is that there is no systematic way within a system of rights to take costs and benefits into account in some "straightforward" way even if we desired to do so. It is this incommensurability that forces us in the end to rely upon a kind of shared collective judgment about where the one set of considerations should dominate the other. The point is of course an embarrassment to my approach to the law, but it is the type of embarrassment that must be accepted whenever the legal system tries to harmonize any two or more values within a single theory.

....

... It is unwise, indeed futile, to attempt to account for the complete structure of a complicated legal system by reference to any single value or principle-be it liberty or efficiency.

Richard A. Epstein, Causation and Corrective Justice: A Reply to Two Critics, 8 J. LEGAL STUD. 477, 503-04 (1979).

${ }^{49}$ See George P. Fletcher, The Right and the Reasonable, 98 HARV. L. REV. 949 (1985). In fact, Fletcher characterizes the sort of structured legal theory he favors as "monistic" (and the alternative theories he likes less well as "pluralistic"). See id. at 980-82. This claim has attracted criticism. See infra text accompanying note 68 (discussing Weinrib's criticisms of Fletcher). On close analysis, Fletcher's theory appears to be pluralistic (as the critics suggest), but conceptually ordered (a possible answer to the criticisms). See infra text accompanying notes $60-74$. 
Fletcher assigns to the concept of excuses in his work on the criminal law.

Fletcher begins by distinguishing two types of legal thinking, "flat" and "structured," which he associates with the common law and civil law systems, respectively. ${ }^{50}$ Flat legal thinking, according to Fletcher, "proceeds in a single stage, marked by the application of a legal norm," such as reasonableness, "that invokes all of the criteria relevant to the resolution of a dispute." In this respect, flat legal thinking appears to assume a kind of commensurability across the plural criteria; there is, at least, some kind of single-stage (possibly intuitionist) accommodation of the different criteria going on.

Structured legal thinking, on the other hand, proceeds in two stages: First, what Fletcher refers to as an "absolute norm," such as the German concept of Recht (objective Right), is asserted; and, second, "qualifications enter to restrict the scope of the supposedly dispositive norm." ${ }^{52}$ Structured legal thinking, therefore, looks to be much more like the sort of defeasible legal reasoning that we have already seen in the analyses of both Hart and Epstein.

It is at the second stage of the structured analysis, says Fletcher, that the important concept of criminal law excuses comes in. ${ }^{53}$ Moreover, as Fletcher argues, it is only at the second stage where this concept, and the values that it incorporates, could possibly come in. For the notion of an excuse is an essentially (conceptually) sequenced idea; without a prior act of wrongdoing, there is nothing for which the actor can be held responsible, and no issue, therefore, to which an excuse could possibly have any sensible application. ${ }^{54}$ In addition, excuses also presuppose, even further back in the conceptual sequence, the possibility of (full) human agency; hence, we do not seek to excuse natural events, such as a rainfall or an avalanche, ${ }^{55}$ or (more controversially perhaps) the harmful consequences caused by an in-

50 Fletcher, supra note 49 , at $950-54$.

${ }^{31}$ Id. at 951.

${ }^{52} I d$

${ }^{53}$ See id. at 957-62 (discussing justification and excuse in the context of structured legal argument).

${ }^{34}$ See id. at 960 ("Excuses make sense only in the context of precluding blame and thus presuppose the possibility of blame.").

${ }^{55}$ See id. (noting that it makes no sense to "excuse" natural occurrences because if there is no person to hold responsible, there is no question of blame). 
fant or an insane person. ${ }^{56}$ Thus, the very concept of an excuse would seem to have at least three (not merely two, as Fletcher sometimes suggests) stages of analysis: (1) Is the actor excused (where the concept of excuse presupposes wrong)?; (2) Did the actor do wrong (where the concept of wrong presupposes the concept of Right)?; and (3) Did the actor have the capacity for agency (where the concept of Right presupposes agency)? Of course, as these three stages apply only to the conceptual presuppositions, a suitably structured adjudicative process concerned with these concepts would have to address each of the questions in the reverse order of their presentation here.

This much suggests that Fletcher's analysis of criminal law excuses is conceptually sequenced. In this respect, therefore, there is a very self-conscious ordering of legal concepts that is noticeably lacking in Epstein's analysis. Epstein, however, is more focused on the values that are so important to public decisionmaking in general, namely individual rights and social welfare. ${ }^{57}$ The question that now arises is whether Fletcher's conceptually sequenced invocation of excuses can bring order to those sorts of values in a way that respects their incommensurable pluralism. To explore this possibility further, we need to know more about the values that animate Fletcher's notion of excuse.

For Fletcher, as already indicated, the first stage of any criminal law structure "addresses itself to the criteria of security and personal freedom, the values embodied in the traditional conception of Right. ${ }^{, 58}$ In this respect, Fletcher's first-stage concern is very similar to Epstein's concern about the plaintiff's prima facie right against invasion. ${ }^{59}$ Moreover, the second stage of Fletcher's structure also invokes an interpersonal concern for welfare that is comparable (but not identical) to Epstein's concern for social utility. According to Fletcher, "[t]he second level softens the harshness of this absolutist

${ }^{56}$ Such persons are not so much excused from their wrongdoing as they are $e x-$ empted (perhaps only temporarily in the case of insanity) from the very applicability of the idea of wrongdoing.

${ }^{57}$ See supra text accompanying note 42.

${ }^{5 s}$ Fletcher, supra note 49 , at 969 .

${ }^{59}$ By emphasizing both personal security and freedom, Fletcher does a better job than Epstein of attending to the equality of agency that is the proper concern of Right. Epstein's system of strict liability puts too much emphasis on the security of the plaintiff and ignores the equal possibility for freedom that is at stake in the agency of the defendant. For some theorists of tort law, a concern for the equal agency of the plaintiff and the defendant requires that there be an objective standard of fault, not strict liability. See, e.g., ERNEST J. WEINRIB, THE IDEA OF PRIVATE LAW 177-83 (1995) (arguing that strict liability and the subjective standard focus on only one of the parties, whereas corrective justice treats the litigants as equals). 
view [of Right] by introducing criteria of human solidarity. In going from the first to the second level, we shift from rights to interests."

Specifically, the softening value that seems to inform Fletcher's notion of excuse at the second stage is humanitarian compassion. ${ }^{61}$ Typically, where excuses are at stake, the defendant claims to have committed a wrong "under circumstances of duress, personal necessity, unavoidable ignorance of the law, and mental disturbance," all situations where, Fletcher suggests, "wrongful actors deserve our compassion. $^{.62}$ Indeed, Fletcher goes further, arguing that the defendant not only deserves our compassion, but also has a right to it. ${ }^{63}$ This much, Fletcher has argued elsewhere, follows from the idea of equality, a value that informs the criminal law action from its firststage beginnings under the aspect of Right through to the exercise of compassion in the decision to excuse. ${ }^{64}$ Criminal wrongdoing (advertently) denies the possibility of equal agency that it is the business of Right (and the state as guardian of the category of Right) to protect. ${ }^{65}$ But if the accused has done only what compassion tells us we would have done ourselves in like circumstances, then a complete realization of the equality that criminal wrong denies requires us not to punish. Punishment in the face of such a finding, rather than manifesting our equality with the accused, has the appearance of inequality and is, therefore, positively unjust when viewed within the egalitarian framework of Right. ${ }^{66}$

${ }^{60}$ Fletcher, supra note 49 , at 969.

${ }^{61}$ See id. at 968-71, 971 (" [C]ompassion comes center stage in the recognition of mitigating and excusing circumstances that reduce or eliminate the punishment deserved by the wrongdoer.").

${ }^{62}$ Id. at 970 .

${ }^{63}$ See id. (discussing the right to be excused).

${ }^{64}$ See George P. Fletcher, The Individualization of Excusing Conditions, 47 S. CAL. L. REv. 1269, 1283 n.49 (1974) ("Compassion ... is always expressed among persons on an equal plane; it is not the forfeiture of a right or power, but the recognition that there is no basis in the facts for claiming a right or power over the object of compassion.").

${ }^{65}$ For a more detailed explanation of the relevance of Right to an integrated understanding of the role of the state in prosecuting criminal law actions, the subjective mens rea requirement as the standard of fault, and the need for certain excuses to complete the criminal action, see Bruce Chapman, $A$ Theory of Criminal Law Excuses, 1 CAN. J.L. \& JURIS. 75, 80-86 (1988), which proposes, in part, that "the criminal law action begins as an action on behalf of the category of right."

${ }^{66}$ See Herbert L. PACker, The Limits of the Criminal Sanction 118 (1968) (arguing, similarly, that " $[t]$ he law that exacts more of an individual than its framers could give under the same circumstances is simply hypocritical"). 
Filling in the formalities of a conceptually sequenced structure with any account of substantive values is not without its perils. Sometimes the values simply will not fit without doing conceptual violence to the overall structure. Indeed, one interpretation of Epstein's concerns $^{67}$ is that the invocation of utilitarian considerations, even at the second, affirmative-defenses stage of a legal action, would obliterate the structure provided by the priority of individual rights.

It should not be surprising that Fletcher's structured analysis also has attracted this kind of criticism. Ernest Weinrib, for example, has argued that Fletcher's structure amounts to no more than the same "tolerant muddle" that Fletcher himself has criticized as characteristic of much flat legal thinking:

Fletcher's structured style of argument is in its own way a muddle due to the lack of coherence between the two tiers of the structure. While the two tiers together form the structured thinking yielded by the conception of right, only the first tier presents an argument of right; the second tier of compassionate considerations somehow belongs to the structure of right without itself being an argument of right. The relevance of an argument of right in the first stage is thus merely the reflection of characterizing the paradigm in terms of right. The humanitarian second stage seems to be nothing but an ad hoc moderation of right's inherent coldness of heart.

Fletcher's portrayal of the relationship between justification and excuse makes the relationship seem entirely a matter of their sequencing in structural thinking; it does not address why the elements of the sequencing be brought together at all. These elements go to the different issues of act and blameworthiness, and Fletcher seems to conceive of each of them as having an independent validity.... [E] ach could appropriate the whole field. From the standpoint of criminal law, the initial focus on the act is understandable, but then why should we pay any attention to the issue of excuse? Conversely, why is the blameworthiness of the actor important enough to claim part of our attention but not all of it? Nothing seems to hold the two disparate elements together except that they happen to be situated in the sequenced conception of criminality. The second tier is piled on to the first tier without their being inwardly connected. In other words, Fletcher proposes structure without unity.

Thus, while the notion of excuse might seem to reflect the conceptual sequencing that Fletcher claims it does, Weinrib objects that this structure, once it is filled in with a substantive concern for both

${ }^{67}$ See supra notes 45-47 and accompanying text.

${ }^{6}$ Ernest J. Weinrib, Law as a Kantian Idea of Reason, 87 COLUM. L. REV. 472, 476 n.10 (1987). 
the heartlessness of rights and the solidarity of our compassion for the defendant's interests, lacks overall coherence.

However, Weinrib's critique of Fletcher pays insufficient attention to the important advantage that follows from introducing plural considerations via a conceptually ordered sequence rather than simultaneously, as in flat legal thinking. Compassion, as an independent idea, is obviously very different from heartlessness; without moreunder a "flat" comparison-it seems true that these two would be incoherent or even contradictory. However, the sort of compassion that Fletcher has in mind is ordered by the concept of excuse. It only becomes an issue in the criminal law action once the defendant already has been shown to be a wrongdoer and, therefore, liable to punishment. $^{69}$ It is for this reason that Fletcher says that the right to be excused "applies only against the courts," coming into play ex post at the time of the trial. ${ }^{70}$ It would be wrong, for example, for the defendant ex ante to invoke our compassion for her preoffense circumstances, claiming that she had a right to engage in the wrongful act and, further, that her victim had a correlative duty to submit to it. This would truly allow compassion to obliterate the Right. But if our compassion is limited to the moment where punishment is at issue, that is, where wrongdoing has already been shown, then the priority of Right in general and, more particularly, the right of the victim to act reasonably in self-defense, are preserved. ${ }^{71}$

Weinrib might object to Fletcher's invocation of compassion for the defendant in her circumstances for a different reason. He might say that such compassion is at odds with the very idea of equal freedom that Right makes possible. After all, the notion of freedom that Fletcher uses is overtly Kantian: the freedom of persons capable of rising above their particular circumstances and acting independently

${ }^{69}$ The idea that the normative criteria establishing wrong have to be in place and complete even before the normative criteria behind the notion of excuse can arise is important for yet another reason. It shows that the prima facie case is not merely prima facie because information is (so far) incomplete, the sort of argument one might expect from an economist, for example. If information on the prima facie case were incomplete, however, then there would be no case to answer and no need to consider excuses. Excuses work at the margins of completeness, not incompleteness, in the development of a case.

${ }^{70}$ Fletcher, supra note 49 , at 970.

7 Self-defense involves a justified use of force by $A$ against wrongdoing by another, $B$. Thus, if our compassion for $B$ in her circumstances negated her wrongdoing rather than merely excused her from punishment, we would lose the possibility of $A$ using self-defense as a justification. For discussion of this sort of example in much greater detail, see id. at 972-73. 
of them. To build excuses out of compassion for the accused who is, even reasonably, overwhelmed by her circumstances is incoherent with this Kantian notion of freedom. Or so the argument might go.

But again, the reply must be that it is not sufficient merely to point to a countervailing value and suggest that it implies incoherence, particularly within a framework that is attempting to accommodate plural concerns. If the countervailing value can be conceptually ordered and sequenced within the legal action, then attention to it is not necessarily irrational. Thus, a court that considers the particularities of the accused's circumstances after it has come to a proper Kantian judgment of the accused's action in the abstract, as is done when excuses presuppose wrong, does not do conceptual violence to Right. The court can judge a person's conduct to be wrongful, and yet decide not to act on that judgment by punishing her, without in any way denying the Right as a conceptual category. Indeed, as argued above, a complete realization of the equality that wrong denies might require us, as instances of the category of Right (in other words, as rightsholders now acting in the world), not to punish the accused in these sorts of circumstances.

Fletcher's structured account of the criminal law action provides us, therefore, with an example of a conceptually sequenced accommodation of plural values. In the first stage, there is the concept of Right and the possibility of equal freedom that this concept seeks to protect. $^{72}$ All judgments of wrongdoing occur under the category of Right. At the second stage, however, once wrongdoing has been shown, the accused can be excused if our compassion for her in her circumstances seems to require it. ${ }^{73}$ This compassion, of course, serves to defeat what the prior notion of Right initially seemed to require, namely, punishment of the accused. It also seems to incorporate an interpersonal concern for welfare that is not entirely in keeping with the heartlessness of Right, which, typically, limits itself to the virtue of respect. ${ }^{74}$ But that is only what one should expect under a decisionmaking procedure committed to a rational (in other words, conceptually ordered) accommodation of plural values.

${ }^{72}$ See supra text accompanying note 65.

${ }^{73}$ See supra text accompanying note 66.

${ }^{74}$ See DwORKIN, supra note 34 , at $180-83$ (arguing that it is the twin values of equal concern and respect that provide the most principled and fundamental understanding of our common law). Dworkin does not explicitly separate these twin equality values into a conceptually prior and more abstract respect for rights, on the one hand, and a more particular concern for welfare, on the other, as suggested here. 


\section{Weinrib on the Standard of Reasonable Care}

A final example of a conceptually sequenced pluralism comes, somewhat ironically, from Ernest Weinrib. ${ }^{75}$ The irony stems not only from the fact that Weinrib has been a critic of Fletcher's structured legal thinking but, more generally, from the fact that Weinrib's corrective justice theory of tort law stands out from others because of its uncompromising commitment to coherence, a commitment that Weinrib believes is incompatible with pluralism.

For Weinrib, the private law of tort "is a justificatory enterprise." This means that the juridical "relationship between the parties is not merely an inert datum of positive law, but an expression of- or at least an attempt to express-justified terms of interaction." "Coherence," says Weinrib:

must be understood in the light of this justificatory dimension. For a private law relationship to be coherent, the consideration that justifies any feature of that relationship must cohere with the considerations that justify every other feature of it. Coherence is the interlocking into a single integrated justification of all the justificatory considerations that pertain to a juridical relationship. ${ }^{78}$

For Weinrib, the salient features of the tort law relationship that call for such an integrated form of justification are that the plaintiff and the defendant (and only these two) are connected through an "institutional procedure (the plaintiff-defendant lawsuit)" which gives each equal standing, and that there is "an ensemble of doctrines and concepts (cause, fault, duty, remoteness, and so on)" relate only to the nature of their very particular (possibly wrongful) interaction. This justification must confine itself, therefore, to these two parties. It "should be neither more expansive by embracing parties outside the relationship nor more restrictive by applying to one of the parties but not to the other."

Weinrib finds the sort of justification he requires in the relational structure of corrective justice, which puts the interaction between a doer and sufferer of a single transaction at the center of its understanding of wrong. Contemporary scholarship's other justifications

\footnotetext{
75 See WEINRIB, supra note 59.

${ }^{76} I d$. at 32.

7 Id.

${ }^{78} \mathrm{Id}$.

${ }^{73} \mathrm{Id}$.

${ }^{80}$ Id. at 35.
} 
for tort law liability, Weinrib argues, such as compensation and deterrence, are inadequate precisely because they fail to account for the special relationship that exists between the plaintiff and the defendant. Compensation can explain, for example, why damages are paid to the injured plaintiff, but not why the plaintiff must collect these damages from a faulty defendant whose fault is a proximate cause of her injury. For this reason, concerns over compensation, Weinrib suggests, lead more naturally to social insurance schemes than to tort law. ${ }^{81}$ And deterrence rationales can explain why the damages are extracted from the defendant when she is at fault, but not why they are only extracted in this way when the plaintiff has been injured and can show a right to compensation. Deterrence, more logically, would sanction the defendant at every moment of fault, regardless of whether the fault actually resulted in injury. Indeed, we typically see this sort of sanction in regulatory schemes focused on the wrongdoer's conduct. Thus, while compensation values can make sense of the plaintiff's role in the tort action, they cannot explain why that role is arbitrarily cut short by an equal concern for the defendant's fault. And while deterrence theory can justify the requirement that the defendant pay when she is at fault, it cannot show why the free range of deterrence is artificially limited to occasions when the plaintiff suffers and claims damages. Neither of these justifications is permitted, as Weinrib puts it, "to expand into the space that it naturally fills. ${ }^{\text {"82 }}$ Rather, each justification is subjected to a limit, not its own, that from the point of view of the justification in question can only seem "normatively arbitrary." Such arbitrariness is merely what one should expect, Weinrib argues, from an unordered plurality of mutually independent values, the stuff of incoherence. ${ }^{84}$

Weinrib's attempt to account for the major institutional and doctrinal features of tort law under the more single-minded theory of corrective justice is impressive. However, even on his own account, he is not entirely successful in purging tort law of pluralistic concerns-in particular, of a concern both for individual rights and social welfare. Interestingly, however, he expresses this dual concern through a conceptually sequenced argument. This is most clear when he analyzes the standard of care in negligence actions.

\footnotetext{
${ }^{81}$ See id. at 37.

82 Id. at 39.

${ }^{83}$ Id.

${ }^{84}$ See id. at 38.
} 
Weinrib organizes his discussion of the standard of care around an analysis of leading cases in both the Commonwealth and the United States. The tort law defendant breaches the standard of reasonable care when she undertakes an action that imposes an unreasonable risk on the plaintiff. ${ }^{85}$ According to Weinrib, there have been two systematic attempts to unpack the different elements of unreasonable risk. In the American version, exemplified most explicitly by the Learned Hand formula from United States v. Carroll Towing Co., the idea is to compare the risk of loss to the plaintiff with the defendant's burden of taking precautions. ${ }^{86}$ A reasonable person undertakes precautions up to the point where the costs of the precautions equal or exceed the expected loss to the plaintiff. By contrast, Weinrib says, the English and Commonwealth approach, exemplified in Bolton $v$. Stone, "disregards the cost of precautions." ${ }^{88}$

Weinrib argues that the English and Commonwealth approach is less problematic for corrective justice theories because risk is a relational concept in a way that the defendant's burden of precautions is not. ${ }^{89}$ The defendant's burden to take adequate precautions is peculiar to her; this burden should not affect the plaintiff's right to be free from the effects of unreasonable risk. As Lord Reid remarked about the defendant cricket club in Bolton, "If cricket cannot be played on a ground without creating a substantial risk, then it should not be played there at all." ${ }^{90}$ Thus, on the Commonwealth analysis as provided so far, the plaintiff's right to be free of such risk would appear to be absolute.

Weinrib also recognizes, however, that it is an exaggeration to say that the Commonwealth cases disregard the burden of precautions. As he observes, the Commonwealth courts proceed with their analysis of unreasonable risk "in several stages." The first stage asks "whether the risk was 'reasonably foreseeable" - whether it was

${ }^{85}$ See id. at 147 (setting out reasonable care standard).

${ }^{85} 159$ F.2d 169, 173 (2d Cir. 1947) (concluding that the defendant's duty depends on the probability that damage would result, the "gravity of the resulting injury," and "the burden of adequate precautions").

${ }^{87} 1951$ App. Cas. 850 (appeal taken from Eng.).

${ }^{89}$ WEINRIB, supra note 59 , at 148.

${ }^{89}$ See id. at 160 (observing that this characterization of risk was shared by Justice Cardozo); see also Palsgraf v. Long Island R.R., 162 N.E. 99, 100 (N.Y. 1928) (Cardozo, J.) ("The risk reasonably to be perceived defines the duty to be obeyed, and risk imports relation ....").

${ }^{90}$ Bolton, 1951 App. Cas. at 867.

${ }^{91}$ WEINRIB, supra note 59 , at 148. 
"real" or "so fantastic or far-fetched""92 that a reasonable person would not have paid much attention to it. Then, having passed "over this undemanding threshold, ${ }^{n 93}$ the court asks what a reasonable person would do in the face of a "real" risk. Real risks fall into two categories: "substantial" (which does not mean large), and "small." substantial risks, the burden of precautions is irrelevant; the defendant can be liable in a Commonwealth court even for cost-justified, or efficient, action. But for small (insubstantial) risks, which normally would not attract liability, the burden of precautions becomes relevant at a third stage of analysis. In particular, there can be liability for small risks that do not involve "considerable expense to eliminate." Thus, while the burden of precautions (even if large) can never contract the scope of liability at a second-stage determination that the risk is substantial, it can work to enlarge the scope of liability at a third stage for small risks if the burden of precautions is small. ${ }^{96}$

Weinrib rightly points out that this third-stage attention to the burden of precautions is a long way from the Hand formula, which considers the burden of precautions at every stage and for all risks. ${ }^{97}$ That is only to say, however, that the concern for efficiency (or total welfare) that is evidenced here-the fact that reasonable persons, when they can, undertake cheap precautions to avoid small risks-is catered to only partially, that is, in a way that avoids full commensurability of rights under the aspect of welfare. The latter, of course, would make a nonsense of a genuinely plural (in other words, independently significant) consideration of welfare and rights. But Weinrib fails to recognize adequately that the Commonwealth cases that he chooses to illuminate the notion of reasonable care are cases that admit plural considerations. These welfare concerns would never be considered at all if, as he suggested initially, precaution costs were really "disregard[ed]."

Moreover, this sequenced accommodation of welfare by way of the efficient avoidance of small risks is conceptually ordered. The

${ }_{92}$ Id. at 148-49 (quoting Wagon Mound No. 2, [1967] I App. Cas. 617, 641 (P.C.

1966) (appeal taken from N.S.W., Austl.)).

99. Id. at 149 (footnote omitted).

${ }^{94} I d$.

${ }^{95}$ Wagon Mound No. 2, [1967] 1 App. Cas. at 642.

${ }^{96}$ See AlAN BRUDNER, THE UNITY OF THE COMMON LAW 191 (1995) (characterizing the burden of precautions as expanding, but not contracting, the scope of liability).

${ }^{97}$ See WEINRIB, supra note 59, at 150.

${ }^{98} I d$. at 148 . 
conceptual ordering borrows from the priority of the Right to the Good, which requires the first stage of the analysis to respect the plaintiff's right to be free of the risk of physical loss even if the defendant's burden of precautions is large. No social calculus that privileges only one side of a wrongful interaction can fairly exculpate the defendant from wrongdoing. ${ }^{99}$ Reasonable persons do not impose their own special problems on others. On the other hand, a genuinely plural concern for an independent notion of welfare (in other words, one not under the aspect of Right ${ }^{100}$ ) does put in an appearance under the standard of reasonable care. Provided they can do so cheaply, reasonable persons do restrain themselves from injuring others even if the risks of injury are otherwise small enough that they are, rightfully, not their concern. This limited concern for welfare can, it seems, defeat the priority of right as recognized at the first stage. It can inculpate but not exculpate a wrongdoer. Welfare, therefore, under a conceptual ordering, has a direction as well as a weight. This is exactly what should be expected under a pathdependent integration of multiple values into a coherent social choice.

This analysis of Weinrib's account of reasonable care is important because it suggests how much can be done, conceptually, merely by altering the order in which values are considered, without introducing some overarching concept like excuses or equality. For rights to be taken seriously, for example, it may be less important that they "trump" utility in any absolute sense than that they be considered

${ }^{99}$ In this respect, contrast the exculpatory effect of an excuse within Fletcher's structured legal thinking, where the excuse, by way of compassion, reaches both parties equally, with the one-sided invocation of high precaution costs. See supra note 64 and accompanying text (discussing Fletcher's argument that compassion must be expressed equally to all parties).

${ }^{100}$ Of course, even for Weinrib, there is a need to attend to welfare issues in tort law. However, welfare has no independent normative significance within his theory; it only has significance under the aspect of rights. For example, we attend to the welfare of the plaintiff in the assessment of damages if (but only if) the plaintiff can show a violation of her rights, and then only to the extent that attending to welfare redresses the rights violation. I have argued elsewhere that Weinrib's limited concern for welfare implies a very limited recovery for nonpecuniary losses. See Bruce Chapman, Wrongdoing, Welfare, and Damages: Recovery for Non-Pecuniary Loss in Corrective Justice, in PHILOSOPHICAL FOUNDATIONS OF TORT LAW 409, 412-25 (David G. Owen ed., 1995) ("[A] limited right of recovery for non-pecuniary loss is an implication of Weinrib's theory of corrective justice."). Welfare under the aspect of deterrence of the sort discussed in the text, however, is welfare beyond the aspect of right. This may be incoherent for Weinrib, but it should be expected as part of any attempt to accommodate plural values. 
prior to utility in some sequence. Hence, there is the familiar refrain that "The Right is prior to the Good." The alternative sequence, which puts the Good before the Right, tends to reduce the Right to insignificance, thus failing to "take rights seriously." mistake to think that this priority is nondefeasible. Concern for the Good, or, as in the torts cases that Weinrib analyzes, concern for the easy avoidance of accidents, can be such that the Right must yield. Nonetheless, just as it is a mistake to think that the priority of Right means absolute priority, it is also a mistake to think that the nonabsolute priority of Right means that it has no priority at all. A sensible or "serious" invocation of the Right means that the Right applies categorically, even if not absolutely, and that there will be some categories or partitions of choice for which the Right is the only applicable value. We can reasonably hope by now that this too is a familiar enough refrain.

\section{ARgument AND tHe ReAsonable Person}

So far in this analysis of a conceptually sequenced accommodation of pluralism, the idea of an "argument" has not had a central role. It is as if an isolated deliberator could just as easily work through the conceptual requirements, and the sequenced pluralism they entail, to reach a rational "all-things-considered" judgment as could two interlocutors in a conversation, or two parties in a dispute. And that is probably true, at least on the argument presented here.

${ }^{101}$ This language should be familiar to those who have read the work of Ronald Dworkin. Dworkin defines a formal right in contradistinction to a collective goal, such as social utility. See DWORKN, supra note 34, at xi ("Individual rights are political trumps held by individuals. Individuals have rights when, for some reason, a collective goal is not a sufficient justification for denying them what they wish, as individuals, to have or to do, or not a sufficient justification for imposing some loss or injury upon them."). Dworkin is also explicit that rights, and the world of principle that supports them, need not be absolute in their limiting effect on the achievement of collective goals. See id. at 92 ("Rights may also be less than absolute; one principle might have to yield to another, or even to an urgent policy with which it competes on particular facts. We may define the weight of a right, assuming it is not absolute, as its power to withstand such competition.").

Dworkin's way of putting the argument invites the criticism that rights are not really trumps, but rather are simply one normative value among others, including social utility, all of which go into an overall calculus of net advantage armed only with their particular "weights." By contrast, the joint accommodation of rights and utility under a conceptually sequenced argument, where rights have both weight and direction (or priority), can make sense of rights as less than absolute "trumps," without reducing them to something merely to be traded off against social utility. Their priority prevents the latter. 
The accommodation of plural criteria into a rational all-thingsconsidered individual choice presents us with much the same theoretical problem as does the rational accommodation of plural values advanced by different individuals into a sensible (and sensitive) social choice. $^{102}$

Nevertheless, I want to emphasize how the account of pluralism provided here might be used to characterize a reasonable person's conduct in an interpersonal setting, such as an exchange of views, or even an argument. Reasonable persons in such situations advance their views openly, nondefensively, and in a nondogmatic way. They are prepared to listen to others' countervailing views. This openness may even be, on the arguments presented in this Article, what makes these persons reasonable as opposed to merely rational. ${ }^{109}$

However, reasonable persons, while open-minded, are not simply at sea, awaiting the next wave of objections to carry them off in a different direction. As Hart's analysis of defeasibility reminds us, until a compelling objection or defense comes along (the "unless" clause that Hart discusses), ${ }^{104}$ they have the courage of their individual convictions, confident that, at least on the argument so far, theirs is the correct position or course to hold.

A reasonable person, therefore, manifests both aspects of defeasibility. She is in one sense fixed in a set of values, and is as sure of them as anyone should be at that point in her deliberation. But she is also constantly open to persuasion, and the possibility that rational argument (rational in that it addresses the very matters that her own position has put at issue) might require an adjustment of her views. It is common these days to make fun of the reasonable person who is so

${ }^{102}$ This point has been well-recognized in the social-choice literature. See, e.g., KENNETH J. ARROW \& HERVÉ RAYNAUd, SOCIAL CHOICE AND MULTICRITERION DECISION-MAKING (1986); see also SUSAN L. HURLEY, NATURAL REASONS 225-70 (1989) (criticizing the extension of the social-choice model into multicriterial individual choice). Hurley, however, is not as critical of the general idea of extending social choice to multicriterial individual decisionmaking as she is of the uncritical use of the original Arrow conditions, and the independence of irrelevant alternatives conditions in particular. See supra note 19 (discussing irrelevant alternatives).

${ }^{103}$ See Richard Rorty, Science as Solidarity, in THE RHETORIC OF THE HUMAN SCIENCES 38, 40 (John S. Nelson et al. eds., 1987) (characterizing the rational person as someone willing to listen and be open to the views of others). I contrast the rational and the reasonable person here only because it seems that some of the features of reasonableness, which I have captured in the idea of defeasibility or path dependence, are at odds with the rationality requirements of rational choice theory. See supra Part II.

${ }^{104}$ See Hart, supra note 30 , at $147-48$. 
much a part of our law; but surely both of these are traits of character any person should be proud to have. 